\title{
Changing Students' Approach to Learning Physics in Postsecondary Gateway Courses
}

\author{
Calvin S. Kalman ${ }^{1}$, Bruce M Shore ${ }^{2}$, Mark W Aulls ${ }^{2}$, Tetyana Antimirova ${ }^{3}$, Juss Kaur Magon ${ }^{2}$, Gyoungho Lee ${ }^{4}$, \\ Ricardo Coelho ${ }^{5}$, Gul Unal Coban ${ }^{6}$, Xiang Huang ${ }^{1}$, Ahmed Ibrahim ${ }^{7}$, Xihui Wang ${ }^{2}$, Dang Diep Minh Tan ${ }^{8}$, Guopeng \\ $\mathrm{Fu}^{9} \&$ Wahidun Khanam ${ }^{2}$ \\ ${ }^{1}$ Department of Physics, Concordia University, Montreal, QC, Canada \\ 2 Department of Educational and Counselling Psychology, McGill University Montreal, Canada \\ ${ }^{3}$ Department of Physics, Ryerson University, Toronto, Canada \\ ${ }^{4}$ Seoul National University, Seoul, South Korea \\ ${ }^{5}$ Faculty of Sciences, University Lisbon, Portugal \\ ${ }^{6}$ Dokuz Eylul University, Izmir, Turkey \\ ${ }^{7}$ Johns Hopkins University, Baltimore, MD, USA \\ ${ }^{8}$ Tra Vinh University, Tra Vinh Province, Vietnam \\ ${ }^{9}$ University of British Columbia, Vancouver, Canada \\ Correspondence: Calvin S. Kalman, Department of Physics, Concordia University, Montreal, QC, Canada. E-mail: \\ Calvin.Kalman@concordia.ca
}

Received: August 17, 2017

Accepted: September 5, 2017

Online Published: September 10, 2017

doi:10.5430/irhe.v2n3p16

URL: https://doi.org/10.5430/irhe.v2n3p16

\begin{abstract}
This study investigated if and how a combined set of specially developed activities can help students change their approach to learning physics. These activities included (a) reflective-writing activities, (b) critique-writing activities, and (c) reflective write-pair-share activities combined with conceptual-conflict collaborative-group exercises. Each of these activities was previously successfully tested as a stand-alone activity. This investigation was conducted at two different institutions over a three-year period. At each institution the same instructor taught students in two sections. At the first, a university with a substantial graduate school, sections were relatively large (over 100 students each) covering a typical introductory calculus-based mechanics course. At the second, a community college, there were relatively small classes (32 students each) covering a typical algebra-based introductory course in mechanics, electricity, and magnetism. The courses at the two institutions used different textbooks and had different formats. Measured data included student interviews and writing products. We developed rubrics for evaluation of the impact of the writing products and interviews of students. The main results of this study were the changes in students' approaches to learning physics, especially as revealed in the interviews. Students who experienced the full suite of activities (a) changed their understanding of physics from solving problems to creating a network of interrelated concepts, and they also (b) modified their approach to learning physics from repetitious review to consideration of the interconnections of the subject matter and (c) related their new learning to key concepts in an overall physics framework.
\end{abstract}

Keywords: science education, epistemology, inquiry, reflective writing, critical thinking

\section{Introduction}

The purpose of this study was to investigate if and how the combined implementation of an entire suite of interventions could change students' approach to learning physics over and above the impact of each approach undertaken alone, and also if it could enhance their learning.

There has been a great deal of research about interventions in courses (we are using the word "course" in the North American sense of a sequence of 13 to 15 weeks of classes on a topic, typically called a "subject" in British and other usage). A gateway course in this context is a course that students need to pass to gain entry to further or advanced 
study in their desired subject. Sometimes there is a comparison between a course using a particular intervention and a lecture-based course. Occasionally there is a comparison to the use of other interventions within a course. At other times there is a measurement of the effect of an intervention on improving student scores on a given instrument between a pre- and a post-test. Such studies are all about what students learn in the classroom, that is, did they understand certain content better with a given intervention? We are concerned in this study with how students learn including the problems with the ways many students try to learn in gateway physics courses.

In this study, instead of using a single intervention under controlled or laboratory conditions, we used a suite of previously validated interventions in real classrooms and courses. Each of these activities has been demonstrated to be effective in promoting conceptual learning as stand-alone activities (Kalman, \& Rohar, 2010). These individual interventions in the suite are summarized in the literature review below. We attempt to show that we get better results in changing students' approach to learning physics with multiple interventions.

\section{Background and Review}

Students have trouble understanding scientific concepts. Additionally, many physics students seem to have trouble connecting the jig-saw puzzles of all the major scientific concepts to see a holistic picture. This study examined interventions that could help students with both of these tasks. In our many years of previous studies building the elements of this university classroom-based experiment, we knew that individual interventions that we had developed had some impact, but we and others have not examined the impact of simultaneous, substantial, instructional changes within ongoing gateway physics courses.

\subsection{Concepts, Epistemic Thinking, and Conceptual Change in Learning Physics}

In traditional lecture courses as well as courses that use interactive engagement, students are less expert-like at the end of the course than they were at the beginning (Madsen, McKagan, \& Sayre, 2015). There are a number of influences to take into account in trying to help students become more expert-like in a science course. Firstly, it is necessary to change students' epistemology. Secondly, we need to improve students' critical thinking skills. Thirdly, we need to take account of the long standing debate in the science-education community between those who believe that students come in to the classroom with a theory about the subject that is different from the one described by the teacher and found in their textbooks and those who feel that students' knowledge consists of isolated structures called phenomenological primitives (p-prims). Finally we have to overcome cognitive dissonance so that students actually perceive the information found in their textbook and presented in the classroom. In this section, we will discuss each of these topics.

Because epistemological sophistication is regarded as a desired educational outcome, efforts are necessary to promote its growth. For example, instructional interventions designed to enhance epistemic change in learners have been designed and conducted in different subject areas such as physics (Kalman, Sobhanzadeh, Thompson, Ibrahim, \& Wang, 2015); Karakostas \& Hadzidaki, 2005), mathematics (Bielaczyc \& Kapur, 2010; Liu, 2009; Mason \& Scrivani, 2004), teacher education (Brownlee, 2003; DiPietro, 2004; Gill, 2004; Hong \& Lin, 2010; Marra, 2005), or generally (Elen \& Clarebout, 2001). Different strategies have been used, including epistemic games (Bielaczyc \& Kapur, 2010), explicit reflection or discussion (Kalman \& Rohar, 2010; Yacoubian \& BouJaoude, 2010), and argumentation (McDonald, 2010). Very encouragingly, these studies all support Schraw and Sinatra's (2004) claim that "belief change can be brought about through wrestling with difficult issues" (p. 96) and instructional intervention. Our activities aimed to have students rethink what they already know, to identify the conflicts, and to solve the conflicts through reflection and argument.

"Enabling students to think critically is one of the central objectives of liberal and professional education" (Nelson, 1994, p. 45). What then is critical thinking, and is this a domain-specific attribute or does it involve general principles that, once learned, can be applied across the disciplines? Surveys of the opinions of philosophers and scientists on the nature of the cognitive and affective strategies required for critical thinking have been done by committees headed by Benjamin Bloom (1956)) and Peter Facione (1990)). Bloom's taxonomy is a useful reference point to position the learner with reference to critical thinking. As Facione (1990) put it, researchers "have argued that effective and meaningful education requires that curricular, pedagogical and assessment strategies at all levels of education be coordinated so as to foster in students those cognitive skills and habits of inquiry associated with critical thinking. They have made the case that educating students to be critical thinkers is vital for the students themselves and for society in general" (p. 4).

There is a longstanding debate in the science-education community between those who believe that students come in to the classroom with a theory about the subject that is different from the one described by the teacher and found in their 
textbooks, and those who feel that students' knowledge consists of isolated structures called phenomenological primitives (p-prims). The former was the accepted paradigm on student conceptions in science (1970s to 1990s). For example, in mechanics it was thought that students enter the physics classroom with stable and coherent conceptions about the natural world, similar to those held by ancient philosophers and scientists (Wandersee, Mintzes, \& Novak, 1994). However, diSessa published a chapter in Gentner and Stevens (1983) that strongly challenged this view. He argued that "spontaneously acquired" student knowledge consists of isolated structures called phenomenological primitives (p-prims). The dependence of scientific knowledge on p-prims is not generally recognized because "the work being done by p-prims is covert" (p. 16). What is at stake in this debate? If student knowledge is a hopelessly disorganized jumble of ideas, instruction should build scientific concepts from the most productive and familiar "pieces," an approach taken with the bridging technique (Clement \& Rea-Ramirez, 2008). However, if this knowledge is more-or-less coherent, instruction should confront student ideas with logical arguments and experimental evidence, a tactic taken by the elicit-and-challenge approach developed in the seminal work of Posner, Strike, Hewson, and Gertzog (1982; also see Ohlsson, 2011).

Lattery (2016) presented evidence that many students do indeed have theories about the subject, and their theories are different from those described by the teacher and found in their textbooks. He noted, as an example, that in the case he called Anda, we find a student with no formal instruction in the principles of Newtonian mechanics but able to develop "sophisticated arguments" (the long decay model), "extend the scope of a notion" (e.g., pass an internal coherence test), and "talk about tossing and dropping in uniform terms" (e.g. pass an external coherence test). Anda's ideas appear in every way to be theoretically motivated. This student does not represent an isolated case. At the end of chapter 5, Lattery noted "evidence that students (two physical science students and a student majoring in physics) are authentic and creative scientific modelers" (p. 109). The student view of force and motion does not appear to be incoherent or fragmented, but driven by the directional rule $\hat{f}_{n e t} \propto \hat{v}$ (p. 142). These student oral and written comments are just a sample of the data that point to the ability of students to reason from a coherent and alternative view of force and motion, that is, reason theoretically. Similar results have been found over and over again in more than five years of classroom observation. The claim that physics-naïve students do not possess coherent scientific conceptions (e.g., diSessa et al., 2004; Hammer, 1996) is not supported by this evidence.

In such a case there is incommensurabilty between the theory of the phenomena perceived by the student and the accepted scientific theory (Chi, 2013). Chi, Slotta, and De Leeuw (1994) defined conceptual change as learning that changes a pre-existing conception. This definition is based on a basic assumption that the learner has some prior idea or knowledge of the concept. In Chi and Roscoe (2002), Chi clarified her stance on the structures of concepts as embedded in naïve theories. She explicitly claimed that naïve theories and scientific theories are often incommensurate.

In 1962, Thomas Kuhn (1962/1970) and Paul Feyerabend (1962) independently introduced the idea of incommensurability to the philosophy of science. In The Structure of Scientific Revolutions, Thomas Kuhn (1962/1970) used the term "incommensurable" to characterize the holistic nature of the changes that take place in a scientific revolution. The Stanford Encyclopedia of Philosophy (2016) puts it that:

Problems whose solution was vitally important to the older tradition may temporarily disappear, become obsolete or even unscientific. On the other hand, problems that had not even existed, or whose solution had been considered trivial, may gain extraordinary significance in the new tradition. Kuhn concluded that proponents of incommensurable theories have different conceptions of their discipline and different views about what counts as good science; and that these differences arise because of changes in the list of problems that a theory must resolve and a corresponding change in the standards for the admissibility of proposed solutions. (Section 2.2, http://plato.stanford.edu/entries/incommensurability/\#RevParThoKuhInc)

So for example, Newton's theory was initially widely rejected because it did not explain the attractive forces between matter, something required of any theory of mechanics from the perspective of the proponents of Aristotle and Descartes' theories (Kuhn, 1962/1970, 148). According to Kuhn, with the acceptance of Newton's theory, this question was banished from science as illegitimate, only to re-emerge with the solution offered by general relativity. He concluded that scientific revolutions alter the very definition of science itself.

Kuhn continued to emphasize the difference between normal, cumulative growth that does not change existing concepts; such as the discovery of Boyle's law, which left the concepts of gas, pressure and volume and the instruments used to measure them unchanged, from revolutionary discoveries that could not have been made on the basis of antecedently available concepts; such as the discovery of Newton's theory (Kuhn, 2000/1981). Such developments require replacing existing concepts with new concepts that are incompatible with the older ideas. 
Feyerabend (1962) illustrated the incommensurability of scientific theories with a comparison of six pairs of central concepts drawn from three episodes of fundamental theory change in the course of scientific advance. One of these is the dynamical characterization of impetus in the impetus theory of motion and the concept of momentum in the conceptual apparatus of Newtonian mechanics. Chi (2013) noted "that there are numerous false beliefs about concepts such as force-and-motion or heat-and-temperature across a variety of domains for which conceptual change is very hard to achieve. . . . In short, there are many concepts like force and motion, for which one's initial flawed mental model is not transformed to the correct model despite repeated corrections or patchings of the underlying rules ... the revised rules did not transform the flawed mental model into the correct model" (p. 57).

Concerning cognitive dissonance, Festinger $(1957,1962)$ wrote, "In the course of our lives we have all accumulated a large number of expectations about what things go together and what things do not. When such an expectation is not fulfilled, dissonance occurs. . . . He can even distort his perception and his information about the world around him. Changes in items of information that produce or restore consistency are referred to as dissonance-reducing changes" (p. 94)

This is precisely the situation of the typical student in a gateway physics course in mechanics. Students have been experimenting since they were very young and their under- standing of nature clashes with the Newtonian synthesis presented in the classroom and in their textbook. At the same time they have strong beliefs that knowledge is conveyed by authorities such as their instructor and especially the textbook, more so than in their own knowledge (Gabella, 1994; Muis, 2004). This results in cognitive dissonance. To reduce the dissonance between their understanding and what they hear in the classroom and read in the textbook, students mishear the teacher and misread the textbook. Every time that we have given a seminar and mention about students coming up after class and stating that the instructor has said exactly the opposite of what the instructor said everyone in the room, all participants nod their heads.

We conjecture that if students reflect metacognitively on textual material before coming to class and then have interventions in class that have them examine subjects that produce cognitive dissonance, the students' epistemological beliefs would become more expertlike.

\subsection{The Novice-Expert Gap--Coherent Theoretical Framework}

Many novice science learners view science as loosely connected pieces of information to be separately learned, in contrast to the web of meaningful interconnections perceived by science experts (diSessa, 1988; Hammer, 1989, 1994; McCaskey, 2009; Sandoval, 2005). In short, many students do not conceive of science in terms of a coherent theoretical framework. Such a framework is a highly ordered knowledge structure that contains a coherent set of interrelated big ideas. If students thought of science in terms of such a framework they should, as they learn, relate new material to the material that they feel they already understand and in the process assimilate the new material within the framework.

The novice-expert gap is not necessarily reflected in students' science grades or their ability to solve standard, quantitative, end-of-chapter problems (Mazur, 1977b; 1997a). Instead, it is reflected in students' approach to learning and also in the quality of the connections students make among related concepts (Kalman \& Kalman, 1996). More successful students use expert-like strategies more often and more effectively (Kalman, \& Aulls, 2003). Teacher-centered instructional methods, such as traditional lectures, are largely ineffective in helping students acquire expert-like science skills and behaviors (Hake, 1988; Mazur, 2009, 2010).

\subsection{Relating Students Understanding to the Conceptual Physics Framework Presented in the Textbook and by Their Instructor}

Students can compare their conceptual ideas with material from a textbook before the material has been examined in the classroom, using a hermeneutic circle (Kalman, 2011; Lee, Ha \& Kalman, 2013; Gadamer, 1975).

The hermeneutic approach starts by having students initiate a self-dialogue about each textual extract. Within the framework of such a dialogue, there exist two "horizons." There is the horizon that contains everything that a student believes from the particular vantage point of encountering the textual extract. The second horizon encompasses the potential in the textual extract; the sense in which the words, in the textual extract, are related within the language game understood by the author of the textbook. . . . The student approaches the textual extract with preconceptions (misconceptions) about the material within the textual extract. The key quintessential experience occurs when the student is pulled up short by the textual extract. "Either it does not yield any meaning or its meaning is not compatible with what we had expected" 
(Gadamer, 1975, p. 237). At this point the dialogue begins. The student questions what is known within the entire horizon. (Kalman, 2011, p. 163)

Feyerabend (1993, p. 33) pointed out that evaluation of a theoretical framework does not occur until there is an alternative (the principle of counter induction). Using the hermeneutical circle, students can change their thinking to be more expert-like in comparing their conceptual framework with another framework

\subsection{Individual Activities within the Suite of Activities Used in This Study}

Each of these activities, described below, has been demonstrated to be effective for the learning of concepts as stand-alone activities (Kalman, \& Rohar, 2010) using, for example, the Force Concept Inventory (FCI; Hestenes, Wells, \& Swackhamer, 1992). The FCI is a probe of belief systems about mechanics, which has been administered at a large number of universities internationally, and has been validated with similar populations.

We have previously developed and validated the activities in our suite: the Reflective Writing Tool (Kalman, Aulls, Rohar, \& Godley, 2008; Kalman, 2011, Huang, \& Kalman 2012), the conceptual-conflict collaborative-group exercises, Reflective Write-pair-share exercises (Kalman, Morris, Cottin, \& Gordon, 1999; Kalman, 2002, 2006), and the critique-writing exercises (Kalman, \& Rohar, 2010). The importance of following up the conceptual-conflict collaborative-group exercises, Reflective Write-pair-share exercises with the critique-writing exercises was shown in the conclusion of Kalman, Rohar. \& Wells (2004): "The winter 1998 students only participated in collaborative group exercises [including Reflective Write-pair-share]. The winter 1999 students additionally did follow-up writing exercises (critiques). In every case the winter 1999 group scored considerably higher than the winter 1998 group" (p. 716).

Reflective Writing. The term Reflective Writing is used in this study to refer to the use of a form of "freewriting" to interact with material from a textbook before the material has been examined in the classroom in the manner of a hermeneutic circle (Gadamer, 1975; Kalman, 2011; Lee, Ha, \& Kalman, 2013).

In performing Reflective-Writing students employ a hermeneutical circle to understand the material in the textbook reaching out beyond the individual sections of the textbook. They come to realize that they began the course with pre understandings that are not aligned with the framework described in the textbook. In examining this dissonance, they seek to relate passages that they are studying to text found in previous chapters. In doing this they develop a more holistic approach to the course. At the same time they refine and come to a clear understanding of key concepts. (Kalman, 2011)

The goal of a recent study (Huang \& Kalman, 2012) was to explore relationships between students' performance found in their writing products, and their epistemology and way of learning. Students with higher scores on an epistemology survey tended to use reflective writing in a more effective way to enhance their learning of textual material.

Reflective Write-Pair-Share. In the Reflective Write-pair-share activity, students are asked to freewrite for a short fixed time on the material presented on a single projected slide and then share their conclusions with their neighbors. This activity has been discussed but not formally evaluated (Kalman., Aulls, Rohar, \& Godley, 2008). Typically, the mechanics course in which the data were collected began with a description of nature in terms of displacement, instantaneous velocity, and acceleration. As seen in Figure 1, the first two Reflective Write-pair-share activities explored these concepts. Next we used a Reflective Write-pair-share exercise to contrast Galileo's and Aristotle's views about the motion of free-falling bodies near the earth's surface (free fall means we neglect air resistance).

Conceptual-conflict collaborative-group exercises. The conceptual-conflict collaborative-group exercises begin by the creation of groups and group members taking on the roles of timekeeper, critic, facilitator, and presenter. Groups are then asked to solve a conceptual problem. Each group writes down its solution and the instructor asks two or three groups to present their solutions to the full class, and facilitates a wider discussion about the merits of the proposed solutions. The students vote on the various alternatives and the instructor uses observational aids to help the students see which alternative corresponds to experiments. Voting is essential to overcome students' cognitive dissonance and recognize the differences among the various alternatives.

The first conceptual-conflict collaborative-group exercise focused on the independence of horizontal and vertical motion (hence the utility of using vectors in physics). Students were asked to compare the motion of a dropped object with an object thrown horizontally. The second conceptual-conflict collaborative-group exercise was an examination of a sandbag dropped from a hot-air balloon rising at constant speed. The final conceptual-conflict collaborative-group exercise continued the discussion of Galileo's revolutionary idea of inertia. Students were asked 
to examine the forces acting on a thrown baseball just after it leaves one's hand and when it reaches the top of its motion.

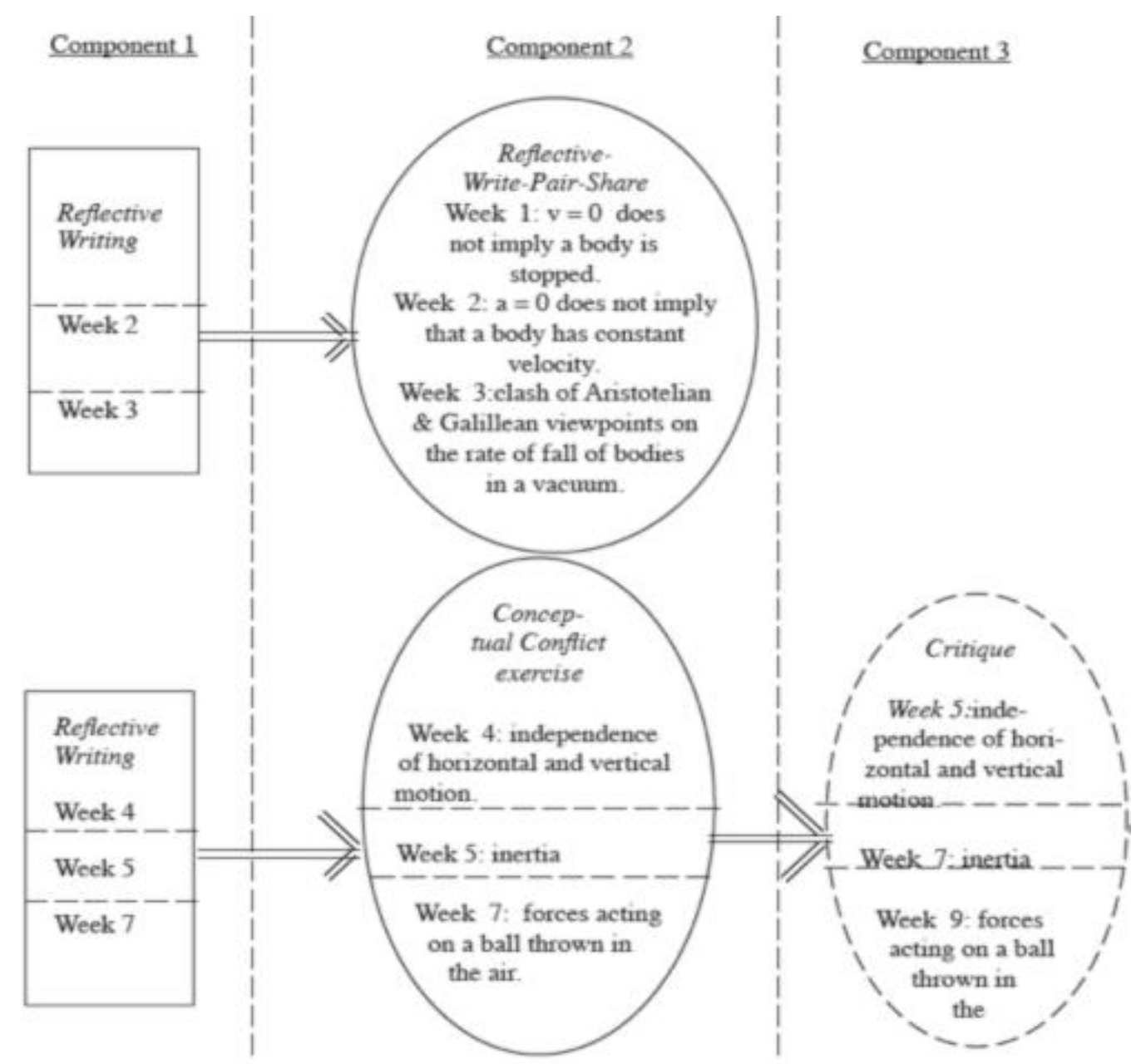

Figure 1. Sequence of implementation of individual activities in the suite

In section A, concept 2 of a bullet compared to a dropped penny and concept 3 of a sandbag dropped from an ascending balloon were treated by the collaborative group method and concepts 1 comparing the fall of a sheet of paper with a set of keys and concept 4 examining the forces acting on a thrown baseball were treated conventionally. In section $\mathrm{B}$, the procedure was reversed--concepts 1 and 4 were treated by the collaborative group method and concepts 2 and 3 were treated conventionally. Standard statistical tests show a gain for the group experiencing collaborative learning over the control group. (Kalman, Morris, Cottin, \& Gordon, 1999)

The conceptual-conflict collaborative-group activity has been compared to peer instruction (Kalman, \& Rohar, 2010). Overall the Collaborative Group method seems to be more effective than the Peer Instruction method. In practice, Reflective Write-pair-share and conceptual-conflict collaborative-group activities were always used in combination. The combined Reflective Write-pair-share and conceptual-conflict collaborative-group exercises dealt with students' personal scientific concepts.

Students will cling to their personal concepts if problems with their personal scientific conceptions do not occur. This is because these beliefs make sense in explaining observations they have made about the physical world, and having taken the effort to construct their private understanding, students will not easily relinquish their original viewpoints. (Kalman, Morris, Cottin, \& Gordon, 1999, p. S48) 
Table 1. Overview of studies comprising the present program of research

\begin{tabular}{|c|c|c|c|}
\hline Study & $\begin{array}{l}\text { Setting and } \\
\text { Population }\end{array}$ & Method & Purpose \\
\hline $\begin{array}{l}\text { Study } 1 \text { (1999) } \\
\text { Kalman, Morris, Cottin, } \\
\text { \& Gordon. }\end{array}$ & $\begin{array}{l}\text { University, } \\
2 \text { groups of students } \\
\text { in two successive } \\
\text { years }\end{array}$ & -Quantitative & $\begin{array}{l}\text { Analyze the collaborative-group } \\
\text { exercise as a stand-alone activity }\end{array}$ \\
\hline $\begin{array}{l}\text { Study } 2 \text { (2004) } \\
\text { Kalman, Rohar, \& Wells }\end{array}$ & $\begin{array}{l}\text { University, } \\
2 \text { more groups of } \\
\text { students in two } \\
\text { successive years }\end{array}$ & $\begin{array}{l}\text {-Quantitative } \\
\text {-Students taught by a different } \\
\text { instructor than in Study } 1 \\
\text { Year 1: As in Study 1, } \\
\text { collaborative group utilized } \\
\text { without follow-up of critique } \\
\text { exercise } \\
\text { Year 2: Collaborative- group } \\
\text { exercise followed up by critique } \\
\text { exercise }\end{array}$ & $\begin{array}{l}\text { Analysis of the Conceptual conflict } \\
\text { model (using collaborative group } \\
\text { exercises) enhanced by the } \\
\text { introduction of the writing-to-learn } \\
\text { exercise ("critique") }\end{array}$ \\
\hline $\begin{array}{l}\text { Study } 3 \text { (2008) } \\
\text { Kalman, Aulls, Rohar, \& } \\
\text { Godley }\end{array}$ & $\begin{array}{l}\text { University } \\
\text { sample of students } \\
\text { from Study } 2 \text {, year } 2\end{array}$ & -Qualitative & $\begin{array}{l}\text { Analyze reflective writing as a } \\
\text { stand-alone activity }\end{array}$ \\
\hline $\begin{array}{l}\text { Study } 4 \text { (2010) } \\
\text { Kalman, Milner-Bolotin, } \\
\text { \& Antimirova. }\end{array}$ & $\begin{array}{l}\text { University, } \\
2 \text { groups of students } \\
\text { in a single semester }\end{array}$ & -Quantitative & $\begin{array}{l}\text { Comparison of the conceptual } \\
\text { conflict collaborative group method } \\
\text { with peer instruction }\end{array}$ \\
\hline $\begin{array}{l}\text { Study } 5 \text { (2010) } \\
\text { Kalman \& Rohar }\end{array}$ & $\begin{array}{l}\text { University, } 2 \\
\text { Colleges. } \\
\text { - } 3 \text { groups of students } \\
\text { in a single semester }\end{array}$ & -Qualitative & $\begin{array}{l}\text { Comparison of students from } \\
\text { University and one College } \\
\text { performing the reflective-writing } \\
\text { activity, collaborative-group } \\
\text { exercise and critique exercise. } \\
\text { Comparison with the second } \\
\text { College was for the } \\
\text { reflective-writing activity only. }\end{array}$ \\
\hline $\begin{array}{l}\text { Study } 6 \text { (2012) } \\
\text { Huang \& Kalman }\end{array}$ & $\begin{array}{l}\text { University and } \\
\text { College. } \\
2 \text { groups of students } \\
\text { in a single semester }\end{array}$ & $\begin{array}{l}\text { - Quantitative scores on a - } \\
\text { Survey; interview transcripts and } \\
\text { students' writing products }\end{array}$ & $\begin{array}{l}\text { Explore if reflective writing enables } \\
\text { dstudents to approach science } \\
\text { textbooks in the manner of a } \\
\text { hermeneutic circle }\end{array}$ \\
\hline $\begin{array}{l}\text { Study } 7 \text { (2013) } \\
\text { Lee, G., Ha, S. \& Kalman }\end{array}$ & University & $\begin{array}{l}\text { - Analyzing group submissions } \\
\text { and written student responses }\end{array}$ & $\begin{array}{l}\text { Analysis of a lesson from a } \\
\text { hermeneutic perspective }\end{array}$ \\
\hline $\begin{array}{l}\text { Study } 8 \text { (2014) } \\
\text { Kalman, Milner-Bolotin, } \\
\text { Aulls, Charles, Coban, } \\
\text { Shore, B. Antimirova, } \\
\text { Kaur Magon, Huang., } \\
\text { Ibrahim, Wang, Lee, } \\
\text { Coelho, R, Tan, \& Fu. }\end{array}$ & $\begin{array}{l}\text { University and first } \\
\text { two years of College } \\
4 \text { groups of students } \\
\text { in a single semester. } \\
\text { ( } 2 \text { groups at each } \\
\text { institution) }\end{array}$ & $\begin{array}{l}\text { - Rubrics on writing products } \\
\text { plus qualitative analysis of the } \\
\text { pre- and post-interviews }\end{array}$ & $\begin{array}{l}\text { Explore if the whole set of } \\
\text { reflective-writing activity, } \\
\text { reflective-write-pair share, } \\
\text { collaborative- group exercise and } \\
\text { critique exercise can change the } \\
\text { way students learn and exceed the } \\
\text { outcomes of stand-alone studies }\end{array}$ \\
\hline
\end{tabular}


The critique activity. The critique activity was introduced to promote critical examination of the alternatives produced in the collaborative group exercise. It is, in essence, an argumentative essay in which students have to put forward as many possible arguments in favor of all the conceptual viewpoints raised in class and then point out which viewpoint is supported by experimental evidence. Students were presented with two scenarios drawn from an earlier conceptual-conflict collaborative-group activity (Wilson, Buffa, \& Lou, 2007). One scenario corresponded to an explanation that does not have experimental validity and the other to the Galileo-Newtonian framework. Both scenarios had been generated by students in the classroom.

The addition of the critique to the conceptual-conflict collaborative-group exercise was based on Feyerabend's principle of counterinduction (1993), the process by which one theory or idea is used to effect change in its rival. In this way an attempt is made to overcome the incommensurabilty between the theory of the phenomena perceived by the student and the accepted scientific theory. The critiques are designed to cause the students to engage in the kind of critical discussion that Feyerabend stated is required to decide which natural interpretations can be kept and which must be replaced.

Critique writing in conjunction with the conceptual-conflict collaborative-group activity has been shown to be effective previously (Kalman, Rohar, \& Wells, 2004, p. 716) using the FCI as a criterion (noted as Study 2 in Table 1). In every case the experimental group scored considerably higher than the control group (these were formally control groups, not just comparison groups). These results were statistically significant. In this improvement on FCI scores, Kalman, \& Aulls (2003) reported moderate success in getting students "to change from a view that science is a matter of solving problems using an independent set of tools, classified according to problem type, to a view that a science subject consists of a web of interconnected concepts" (p. 762). In the study combining the conceptual-conflict collaborative-group with critique writing (Kalman, Rohar, \& Wells, 2004, p. 716), we wish to highlight that, in addition to the statistically significant gains in the two tested concepts, with the addition of the critique activity students also scored better in the baseline consisting of questions that do not relate to the concepts under study. The purpose of the critiques was to enhance the development of students' critical thinking skills so that they would carefully examine the alternatives presented to them in the conceptual conflict exercises. Such a spillover might indicate that, in doing the critiques, students actually do increase their critical thinking skills and that with such an improvement students were led to reevaluate their entire conceptual framework.

As noted at the beginning of this section, many students do not conceive of science in terms of a coherent theoretical framework. We hoped that if we added Reflective Writing we could get students to see the interconnections between the concepts as we had stated,

In performing Reflective-Writing students employ a hermeneutical circle to understand the material in the textbook reaching out beyond the individual sections of the textbook. They come to realize that they began the course with pre understandings that are not aligned with the framework described in the textbook. (Kalman, 2011, p. 170)

In doing Reflective Writing, students make connections between concepts within each chapter and between the chapters. Students were given the following definition of concepts:

concept (Merriam-Webster's Collegiate Dictionary):

2. an abstract or generic idea generalised from particular instances

Concept formation: the process of sorting specific experiences into general rules or classes.

Beyond simple classifications, concepts may also serve as norms or models.]

\subsection{Creating the Suite of Activities}

Table 1 shows how this new study (listed as Study 8) related to the seven prior studies of the stand-alone learning activities. The stand-alone studies (Studies 1 to 4, 6, and 7 in Table 1) and the one-paired study (Study 5) demonstrated the promise of these individual activities, but did not address the potential value-added of using the full, more comprehensive, set of activities and only Study 5 was conducted in multiple institutions.

The specific changes in student learning on which we focused were:

1). The first learning objective for the students was to recognize the importance of concepts in learning physics.

2). The second objective for the students was to modify their learning approach so that they situated concepts within a coherent framework. 
3). The third objective was to enable the students to review their concepts and ask how these concepts fit into the conceptual physics framework presented in the textbook and by their instructor.

\section{Method}

\subsection{Overview}

We studied an extended, multipronged, theoretically, and empirically driven innovation in teaching introductory physics courses that was designed to have a meaningful impact on student learning, and that could be readily adapted elsewhere and in other subjects. To measure if the objectives were met, we employed interviews at the beginning and at the end of the semester as the primary data for this study. We also examined writing products produced by the students each week in the course. During two semesters we interviewed all the students who volunteered to participate in this research project. Thirteen students from the experimental groups were interviewed at the beginning of the course and 13 interviews were conducted at the end. To confirm that students were actually doing what they said they were doing in the interviews, we triangulated the data garnered from the interviews with our analysis of the students' writing products. We also assessed the writing products of students in the same course who had not been interviewed to triangulate with interview data.

We developed the interview questions and the rubrics [simple 3-level "developmental" sequences] to evaluate the interviews and the writing products in the first year of this project, and we pilot-tested them in the second year. We identified recurring general and specific themes that were common to all students, as well as themes that were unique to particular students. In the second year we included a comparison group to refine the interview questions and rubrics, and also to verify the validity of the rubrics. In the third year, research phase, we did not use a comparison group because we were not trying to compare two groups of students. We used the rubrics as an auxiliary tool to the interviews to find out if students using the entire suite of activities changed their approach to learning physics. A fourth year was taken for the analysis of the results. In this analysis, we also employed qualitative methods to look at repeated readings of the interviews for each student.

Conducting the study in realistic instructional conditions was important, although it made it more difficult to implement controlled conditions at the level achievable in a laboratory setting. To ensure that the students who volunteered were typical of all the students in the class we compared the students' writing products of those both interviewed and not interviewed.

\subsection{Setting}

We intentionally looked at the introductory mechanics course taught in very different ways to different-sized classes in two very different institutions over a three-year period. At Institution A, a university with a substantial graduate enrolment, classes were relatively large "sections" ((a subgroup of a students in a course, over 100 students each) of a typical calculus-based course in mechanics. At Institution B, a community college, there were relatively small classes (32 students each) of a typical algebra-based introductory course in mechanics, electricity, and magnetism. Both institutions were in major cities but thousands of kilometers apart. The two institutions used different textbooks and had different formats. At both institutions students were randomly assigned to the two sections by the Registrar's office. All of the students were in their first year of post-secondary study. The majority of students enrolled in these courses were science or engineering majors, with these courses being program requirements. Generally, however, only a small number of students from such cohorts typically continue on with physics as their major subject. There were two instructors, one at each of the two institutions, who were not part of the research team that authored this paper. All sections within each institution, experimental and comparison groups, were taught by the same instructor.

Marks (grades counting toward course performance) were given for Reflective Writing, critiques, and summary writing. The Reflective Write-pair-share combined with conceptual-conflict collaborative-group exercises activities were done by all the students during regular class hours, but did not count in the grades. The Reflective Writing, summary writing, and critiques were assigned as homework. The instructor in Institution $\mathrm{A}$ had a $\mathrm{PhD}$ and a substantial biophysics research program that utilized graduate students. The instructor in Institution B had an MSc. Both instructors had been teaching for many years. At Institution A, the instructor was a colleague of the principal investigator in the same department. He was a traditional instructor relying primarily on lecturing and skeptical about the impact of the interventions. He did not actively talk about teaching for concepts in the experimental or comparison classes, nor about demonstrating the value of concepts through the use of these novel activities. At Institution B, the instructor had taken a workshop on Reflective Writing from the principal investigator and regularly used it in his teaching. Participants were therefore a sample of willing students of cooperating instructors. All students who were willing to participate were interviewed and received a small cash reward for their participation. 
This design might limit generalization of the conclusions, but it had the advantage of authenticity of students in real classes. Precise subsample sizes are indicated with each part of the analysis. The final examinations in both institutions were characterized by traditional problem solving, despite the pedagogical changes for the experimental groups.

Extensive feedback was collected at a series of conferences about the design of the study and, as preliminary data became available, about the analysis.

\subsection{Timetable}

Table 2. Overall design of the study across three years

Pre Study Rudimentary Interview Questionnaire and Reflective Writing Products.

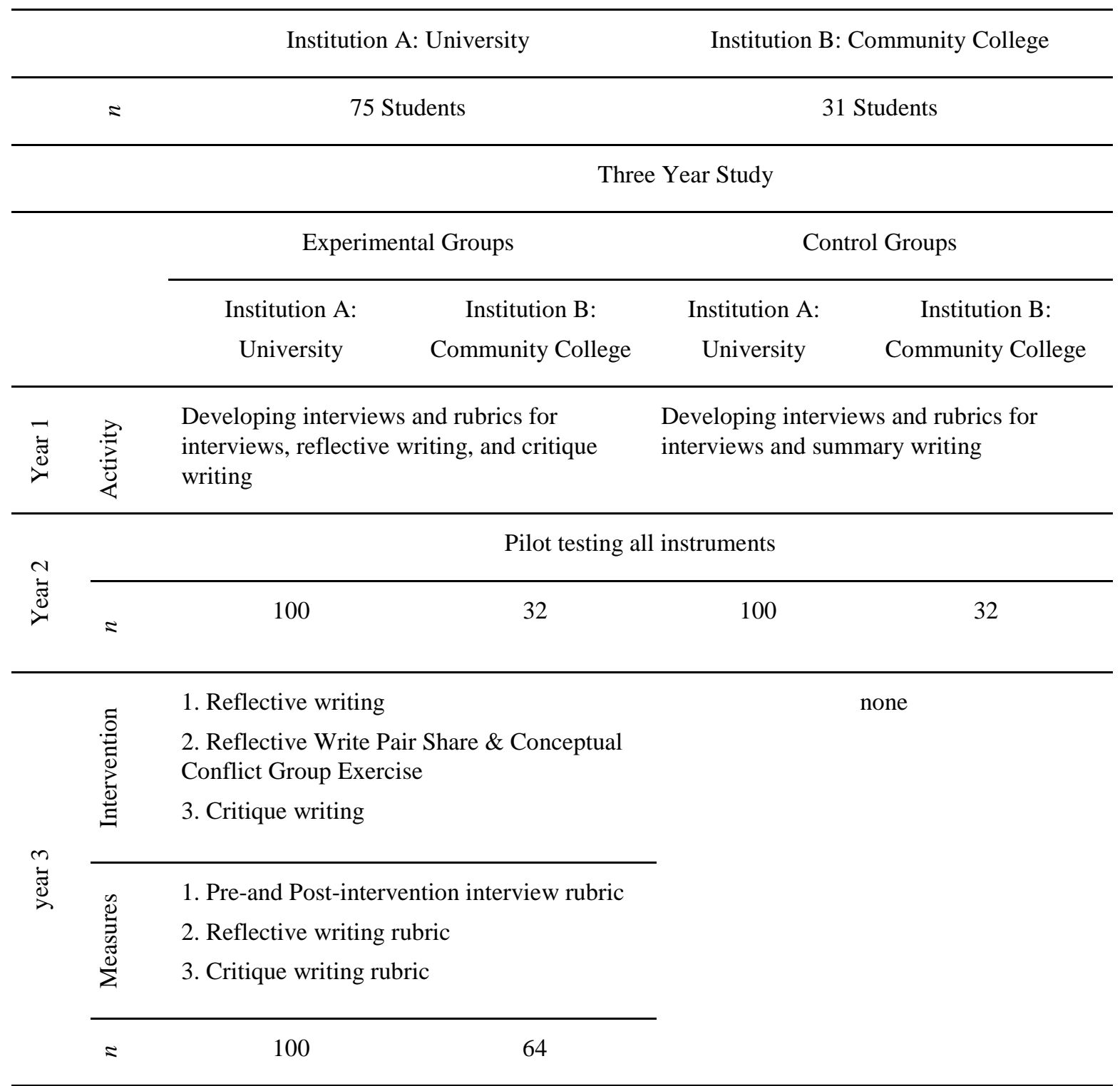


Table 2 provides an overall picture of the study, summarized as follows:

Year 0 (Prestudy): We had access to an Interview Questionnaire and Reflective Writing products used in an earlier study on Reflective Writing (see Table 1, Study 6). The interviews that we developed used the interview questionnaire developed in this earlier study as a starting point. The Reflective Writing products and the interviews from Study 6 were used to help us construct rubrics to analyze the Reflective Writing products and the interviews found in this study.

Year 1: The first year of the project (spring 2010 to fall 2010) was devoted to development of rubrics and interview questions utilizing the data from 2009 courses. Data on students for 2009 are not incorporated in this paper. We also developed rubrics for analyzing the critiques.

Year 2: Pilot-testing of all the instruments (interview questionnaires and rubrics for the interviews and the writing products). In this pilot-testing phase, we used a comparison-group design. One section (experimental groups) in each institution was exposed to all three of the target activities--Reflective Writing activities, critique-writing activities, and Reflective Write-pair-share combined with conceptual-conflict collaborative-group exercises. Students in the other section in each institution (comparison groups) were asked to submit only summary writing of textual material before coming to class. Summary writing is a skill used by many students and for which some research is available showing positive effects of summary writing on recall and understanding (Radmacher \& Latosi-Sawin, 1995). There were roughly 100 students in each section in Institution A and 32 students in each section of Institution B. To test the validity of the rubrics, the interviews and every available written submission from the students were circulated to the authors so that each writing product was evaluated by three different evaluators. A final form of the interview questionnaire and of the rubrics was then produced. The intention of the comparison group design was to provide a benchmark for research undertaken in year 3. The objectives did not require a comparison-group design.

Year 3: One section in Institution $\mathrm{A}$ and both sections in Institution $\mathrm{B}$ were exposed to all three target activities--Reflective Writing activities, critique-writing activities, and Reflective Write-pair-share combined with conceptual-conflict collaborative-group exercises.

Years 4, 5 (analysis of the data from year 3): Every interview and every written product was evaluated by three raters. A total of 249 Reflective Writing products and 64 critiques were analyzed. We also analyzed interviews (preand post-) of five students in Institution A and eight in Institution B. The Reflective Writing products, critiques, and interviews were analyzed using the rubrics and the interviews were also analysed using qualitative methods.

\subsection{Development of the Interview Questions}

The interview questions as an assessment measure were systematically developed in several iterations in team meetings and other exchanges over many). This process focused on crafting the wording of the questions to capture the nature of what we meant by "changing students' approach to learning physics," how we would present the activities, and to develop the questions and rubrics. Specifically, the interview questionnaire arose from empirical studies that suggested novices' view of science differs from that of experts, as discussed earlier. Discussions led to the generation of questions (and ultimately the three scoring rubrics) that addressed issues based around students' providing evidence that they realized that:

- the parts of the textbook were interrelated,

- there was a scientific framework embedded in the textbook,

- there were other ways of learning than those with which they were previously familiar,

- there were different ways of looking at the subject or topic, and

- their learning strategies should include understanding the framework of the subject.

A preliminary form of the questionnaire was used in the pilot test phase (year 2). Based on the responses, a modified form of the questionnaire was utilized in year 3. Interviews were audiorecorded and videorecorded then transcribed.

\section{Data and Rubrics}

Measured data included student interviews and writing products. Because these course conditions are typical of each institution, we were vigilant for different patterns of results in case they needed to be addressed separately.

This study combined qualitative analyses of semistructured interviews with quantitative rating results.

The rubrics for the interviews did not, however, fully cover all of the rich information found in the interviews and thus were followed by a further qualitative analysis to set out categories and to find all information related to these 
categories. These categories ranged from barriers and facilitators, to students' learning, to changes in students' learning strategies. The Reflective Writing and Critiques are very different kinds of writing activities and consequently the rubrics are very different.

The development of the rubrics is described below. The qualitative analysis helped to triangulate the validity of the quantitative results. Based on pilot data obtained in year 1, the rubrics for analyzing the students' Reflective Writing products were designed using a mix of open coding (Glaser, 1999) and a priori codes, based on our previous research (Huang, \& Kalman, 2012) and keeping in mind the initial foci developed for the interviews (outlined just above). In addition, the rubrics were designed to be sensitive to the presence of evidence for the following by students:

- understanding concepts,

- increasing complexity in writing products,

- using self-regulating strategies (e.g., planning, self-correction),

- relating material across different chapters,

- relating new material to their prior knowledge and experiences,

- articulating insight into their own learning processes, and

- distinguishing between concrete and theoretical ideas.

The focus was not on the knowledge they acquired but on their way of acquiring their knowledge.

Several iterations of the Reflective Writing rubric were applied to actual writing products over an extended period until a final version emerged. For the pilot study in year 2 we used the newly developed rubrics to evaluate 11 reflective-writing products, all the instances from students who provided multiple products at different times in their course. We modified the rubrics and in year 4 we analyzed 249 Reflective Writing products from year 3 students.

Rubrics for the critiques were developed following similar principles and procedures. Inter-rater reliability for the rubrics was tested with actual data before the final coding of responses began. Every available written submission from the students in year 2 (a total of 55 products--only a subset of the potential population agreed to make their writing products available as research artifacts) was circulated to the authors so that three different raters evaluated each writing product. In face-to-face meetings, any discrepancies between ratings of every writing sample were examined and discussed until the raters came to complete agreement on how the rubrics were to be used. For the final ratings, as reported below, most of the raters of each product came up with the same score and any other rating differed by not more than one point.

\section{Results}

The student products in year 3 were used to answer our main research question: Did the exposure to the entire suite of activities change students' approach to learning physics over and above the impact of each approach undertaken alone, and also enhance their learning? We do not claim, for example, that the results of the evaluation of critiques were due to the critique activity alone, because this activity was preceded by the conceptual-conflict collaborative-group and the Reflective Write-pair-share activities (as shown in Figure 1). Thus any results on the critique rubrics could be due to Reflective Write-pair-share or conceptual-conflict collaborative-group, or critique, or any combination of the three activities.

\subsection{Three Specific Learning Objectives}

The first learning objective for the students was to recognize the importance of concepts in learning physics. One student in the experimental group had noted, "It is more of a merging of the concepts of energy with more familiar problem-solving strategies." In the interviews, students typically stated that they were "thinking about some of the concepts we are taught for problem solving." At the beginning of the course, students in the experimental group had reported that they searched the textbook for templates to solve problems. As the course progressed, they came to realize that solving problems requires an understanding of concepts. When asked "Why do you think the professor has given you this activity, Reflective Writing?" four of five students in Institution A responded "identifying important ideas." Five of eight in Institution B reported "identifying important ideas."

A total of 34 critiques (students in year 2) were made available to the researchers. Nine of these products were from six experimental-group students at Institution A, and 25 critiques were from 25 students at Institution B. Forty-three more critiques were obtained from 11 students in Institution A in year 3. Three raters evaluated each individual product on a scale of 0 to 3 points in each category. Students who engaged in critique-writing activities acquired the 
skill to write critiques that reflected ability to identify key concepts and other target performance of the present study. In particular, all of the students identified a key assumption or concept for every given viewpoint or scenario.

The second objective for the students was to modify their learning approach so that they situated concepts within a coherent framework. The interview data were separated according to the two institutions for comparison purposes. At both institutions some students exhibited changes in how they viewed. Of particular importance and relevance was that students categorized their view of learning as "Seeing concepts from different perspectives" (five students) and "Seeing physics (or other knowledge) as more than a collection of facts, having a relational structure" (five students). Four out of five students in Institution A and three out of eight students in Institution B responded positively to the direct question, "Have you changed the way you learn as a result of taking this course?" The ways in which this occurred differed from student to student, but all of these students responded in ways that could be reliably coded as "Less reliance on the textbook."

Students who experienced the full suite of activities became more expert-like after the one-semester intervention; they began to see physics knowledge as interconnected and evolving. As shown in their Reflective Writing products, as students learned they related new material to that which they believed they already understood and, in the process, assimilated the new material within their existing conceptual framework. Although all the categories are important, the particularly important category in our rubric for assessing Critiques was "Relates concepts to previously studied concepts." This implied that a student was able to critically evaluate arguments of other students whose viewpoints were different from the one chosen by the student. Most of the critiques exhibited this quality. Every student had at least one score of at least 2 out of the maximum 3 in each criterion category

When asked "Why do you think the professor has given you this activity, Reflective Writing?", four of five students in Institution A and three of eight in Institution B reported "thinking about what you are learning."

The third learning objective was to enable the students to review their concepts and ask how these concepts fit into the conceptual physics framework presented in the textbook and by their instructor. When asked "Why do you think the professor has given you this activity, Reflective Writing?", Three students noted "integrating ideas" and three identified "recognition that disagreements can be good."

Although all the categories are important, the category in our rubric for assessing Reflective Writing that concerns the third objective in this study was "Relates concepts to previously studied concepts". We found that, in Institution A, students did very well in this category, 25 of 27 of them scoring above two on at least one item under this criterion, six of these being a maximum score of 3. Students in Institution B did not perform as well (only two obtained a rating over 2 under this category) but nonetheless their Reflective Writing products usually exhibited evidence of relating concepts to previously studied concepts, even if less frequently. These results suggested that, due to our intervention, students began to see the web of meaningful interconnections perceived by science experts. Students realized that some ideas, facts, or data presented in the textbook were in conflict with their own ideas or preconceptions and then were also able to discuss the conflict. Faced with scenarios in the critiques taken from two different frameworks, students were able to justify the point-of-view of their framework. Students who wrote critiques were able to evaluate arguments based upon a framework that was different from the one chosen by other students. In most of the critiques, the students could justify the Newtonian point of view suggested in the assignment.

\section{Conclusions}

Using the entire suite of activities creates a condition for more effective and expert-like knowledge construction. The suite of activities helped students overcome the tendency for students to comprehend their physics as a loosely organized collection of facts, if organized at all.

The overall goal of the study was "to investigate if and how a set of specially developed activities can help students change their approach to learning physics." The "how" was addressed in the three specific objectives. The "if" was also supported. The ability of the present results to support these claims is partly the result of our having used multiple outcome measures. These are the particular contributions of this study, and are the key difference between this and previous studies summarized earlier. To begin to have a profound impact on how students learn to think like experts in a domain such as physics, in which prior knowledge may be sparse and misconceptions salient, more than single changes are needed in the instruction. Multiple, connected, sustained, and systematically implemented instructional changes may be needed to impact student learning in these ways, moving at least some of them a step toward becoming inquirers in the discipline (Windschitl, 2002, 2004).

The main results of this study were the changes in several (but not all) students' approaches to learning physics as revealed in the interviews. Interview data about how students think about concepts certainly need to be supported by 
data about student actions. We relied on the following sources about student actions: a vast amount of data analyzing students' writing products by means of rubrics, Reflective Writing products done before they came to each class, and the critiques written several weeks after particular classes. Altogether we triangulated the data garnered from the interviews with our analysis of the student writing products. We also assessed the student writing products of noninterviewed students to triangulate the results.

The students gave evidence of how they viewed learning and how they changed their ways of learning as a result of the suite of activities. Student learning shifted toward more expert-like thinking, and demonstrated that easy-to-implement instructional innovations such as the suite of activities described in this study can narrow the novice-expert gap in the ways students engage physics as a subject.

\subsection{Implications for Physics Teaching}

Implementing the pedagogical strategies discussed in this paper has the potential to help instructors in introductory physics courses to empower their students in learning science by learning how to learn. It can help students move from template-driven to paradigm-driven thinking in the subject matter, even in gateway courses. It can help them perform better. Moreover, success in courses resulting from acquiring such strategies could possibly help retain students beyond gateway science courses.

The activities examined in this paper should be built into the evaluation system. Toward this end, it is also important that Teaching Assistants and Laboratory Assistants who may not have experienced such activities themselves are helped to understand that each problem category is not a world unto itself and that they, in their support of teaching and learning, demonstrate these parallels in tutorials and in their feedback. For example, they can relate how certain paradigms in an earlier problem are used again in new situations as the course progresses, and not just tutor the problem of the day. One way to achieve this would be for Teaching Assistants and Laboratory Assistant to attend the classes and participate with the students.

The three specific exercises--Reflective Writing activities, critique-writing activities, and Reflective Write-pair-share combined with the conceptual-conflict collaborative-group exercises--are well described in accessible literature, easy to implement, and do not consume an inordinate amount of class time. They can increase student engagement and interest, and can be easily built into a wide range of instructional situations from traditional lectures, tutorials, and labs, to inquiry-driven and project-based courses. It is important to use a combination of activities--the suite is more effective than any of the single activities on its own--and to make participation compulsory.

\section{References}

Bielaczyc, K., \& Kapur, M. (2010). Playing epistemic games in science and mathematics classrooms. Educational Technology, 50(5), 19-25

Bloom, B. S., \& Krathwohl, D. R. (Eds.). (1956). Taxonomy of educational objectives: The classification of educational goals. Handbook II Affective domain. New York, NY: Mckay.

Bloom, B. S., Englehart, M. D., Furst, E. J., Hill, W. H., \& Krathwohl, D. R. (Eds.). (1956). Taxonomy of educational objectives: The classification of educational goals. Handbook I: Cognitive domain. New York, NY: Mckay.

Brownlee, J. (2003). Changes in primary school teachers' beliefs about knowing: A longitudinal study. Asia-Pacific Journal of Teacher Education, 31(1), 87-98.

Carey, S. (1991). Knowledge acquisition: Enrichment or conceptual change? In S. Carey \& R. Gelman (Eds.), The epigenesis of mind: Essays on biology and cognition (pp. 257-291). Hillsdale, NJ: Erlbaum.

Carey, S. (1999). Sources of conceptual change. In E. Scholnick, K. Nelson, S. A. Gelman, \& P. Miller (Eds.), Piaget's legacy (pp. 293-326). Mahway, NJ: Erlbaum.

Chi, M. T. H. (2013). Two kinds and four sub-types of misconceived knowledge, ways to change it, and the learning outcomes. In S. Vosniadou (Ed.), International handbook of research on conceptual change (2nd ed., pp. 49-70). New York, NY: Routledge.

Chi, M. T. H., \& Roscoe, R. D. (2002). The processes and challenges of conceptual change. In M. Limón \& L. Mason (Eds.), Reconsidering conceptual change: Issues in theory and practice (pp. 3-27). Dordrecht, The Netherlands: Kluwer.

Chi, M. T. H., Slotta, J. D., \& De Leeuw, N. (1994). From things to processes: A theory of conceptual change for learning science concepts. Learning and Instruction, 4, 27-43. 
Clement, J., \& Rea-Ramirez, M. (Eds.). (2008). Model based learning and instruction in science. Dordrecht, The Netherlands: Springer.

DiPietro, K. (2004). The effects of a constructivist intervention on pre-service teachers. Educational Technology \& Society, 7(1), 63-77.

Discenna, J. (1998). A study of knowledge structure of expert, intermediate and novice subjects in the domain of physics. Kalamazoo, MI: Western Michigan State University, Mallinson Institute for Science Education.

diSessa, A. A. (1983). Phenomenology and the evolution of intuition. In D. Gentner \& A. Stevens (Eds.), Mental models (pp. 15-34). Hillsdale, NJ: Erlbaum,.

diSessa, A. A. (1988). Knowledge in pieces. In G. Forman \& P. B. Pufall (Eds.), Constructivism in the computer age (pp. 49-70). Hillsdale, NJ: Erlbaum.

diSessa, A. A. (1993). Toward an epistemology of physics. Cognition and Instruction 10(2 \& 3), 105-225.

diSessa, A. A. (2014). A history of conceptual change research: Threads and faultlines. In R. K. Sawyer (Ed.), The Cambridge handbook of the learning sciences (2nd ed., pp. 88-108). New York, NY: Cambridge University Press.

diSessa, A. A., Gillespie, N., \& Esterly, J. (2004). Coherence versus fragmentation in the development of the concept of force. Cognitive Science, 28, 843-900.

Elen, J., \& Clarebout, G. (2001). An invasion in the classroom: Influence of an ill-structured innovation on instructional and epistemological beliefs. Learning Environments Research, 4, 87-105. http://doi.org/10.1023/a:1011450524504

Facione, P. A. (Ed.). (1990). Critical Thinking: A Statement of Expert Consensus for Purposes of Educational Assessment and Instruction. American Philosophical Association. ERIC Document Reproduction Service ED 315 423. Retrieved from http://files.eric.ed.gov/fulltext/ED315423.pdf

Festinger L. A. (1957). A theory of cognitive dissonance. Stanford, CA: Stanford University Press.

Festinger, L. A. (1962). Cognitive dissonance. Scientific American, 207, 93-106.

Feyerabend, P. K. (1962). Explanation, reduction and empiricism. In H. Feigl \& G. Maxwell (Eds.), Minnesota studies in the philosophy of science (Vol III, pp. 28-97). Minneapolis, MN: University of Minnesota Press.

Feyerabend, P. K. (1993). Against method (3rd ed.). New York, NY: Verso. [All information referred to in this book is also found in the first edition published in 1975.]

Gabella, M. S. (1994). Beyond the looking glass: Bringing students into the conversation of historical inquiry. Theory and Research in Social Education, 22, 340-363.

Gadamer, H.-G. (1975/1960). Truth and method (Trans. G. Barden \& J. Cumming). New York, NY: Crossroads.

Gill, M. (2004). Changing preservice teachers' epistemological beliefs about teaching and learning in mathematics: An intervention study. Contemporary Educational Psychology, 29, 164-185. http://doi.org/10.1016/j.cedpsych.2004.01.003

Glaser, B. G. (1999). Keynote address from the Fourth Annual Qualitative Health Research Conference: The future of grounded theory. Qualitative Health Research, 9, 836-845.

Hake, R. R. (1998). Interactive-engagement versus traditional methods: A six-thousand-student survey of mechanics test data for introductory physics courses. American Journal of Physics, 66(1), 64-74.

Hammer, D. (1989). Two approaches to learning physics. The Physics Teacher, 27, 664-670.

Hammer, D. (1994). Epistemological beliefs in introductory physics. Cognition and Instruction, 12, $151-183$.

Hammer, D. (1996). Misconceptions or p-prims: How may alternative perspectives of cognitive structure influence instructional perceptions and intentions? Journal of the Learning Sciences, 5, 97-127.

Hestenes, D., Wells, M., \& Swackhamer, G. (1992). Force Concept Inventory. The Physics Teacher, 30, $141-157$.

Hong, H. Y., \& Lin, S. P. (2010). Teacher-education students' epistemological belief change through collaborative knowledge building. The Asia-Pacific Education Researcher, 19, 99-110.

Huang, X., \& Kalman, C. S. (2012). A Case Study on Reflective Writing. Journal of College Science Teaching, 42(1), 92-99. 
Kalman, C. [S.], Milner-Bolotin, M., Aulls, M. W., Charles, E. S., Coban, G. U., Shore, B. [M.], Antimirova, T., Kaur Magon, J., Huang. X., Ibrahim, A., Wang, X., Lee, G., Coelho, R. L., Tan, D. D. N., \& Fu, G. (2014). Understanding the nature of science and nonscientific modes of thinking in gateway science courses. In M. F. Taşar (Ed.), Ankara, Turkey: Pegem Akademi (2012, pp. 1291-1299). Proceedings of the World Conference on Physics Education.

Kalman, C. S. (2002) Generating Effective In-Class Discussions. The Successful Professor, 1(5), 7-9.

Kalman, C. S. (2011). Enhancing Students' Understanding of Concepts By Getting Students to Approach Text in the Manner of a Hermeneutical Circle. Science \& Education, 20(2), 159-172.

Kalman, C. S., \& Aulls, M. (2003). Can an analysis of the contrast between pre-Galilean and Newtonian theoretical frameworks help students develop a scientific mindset? Science \& Education, 12, 761-772.

Kalman, C. S., \& Rohar, S. (2010). Toolbox of activities to support students in a physics gateway course. Physical Review Special Topics - Physics Education Research, 6(2), 1-15.

Kalman, C. S., Aulls, M., Rohar, S., \& Godley, J. (2008). Students Perceptions of Reflective Writing as a Tool for Exploring an Introductory Textbook. Journal of College Science Teaching, 37(4), 74-81.

Kalman, C. S., Milner-Bolotin, M., \& Antimirova, T. (2010). Comparison of the Effectiveness of Collaborative Groups and Peer Instruction in a Large Introductory Physics Course for Science Majors. Canadian Journal of Physics, 88(5), 325-332.

Kalman, C. S., Morris, S., Cottin, C., \& Gordon, R. (1999). Promoting Conceptual Change Using Collaborative Groups In Quantitative Gateway Courses. Physics Educational Research Supplement. American Journal of Physics, 67, S45-S51.

Kalman, C. S., Rohar, S., \& Wells, D. (2004). Enhancing conceptual change using argumentative essays. American Journal of Physics, 72, 715-717.

Kalman, C. S., Sobhanzadeh, M., Thompson, R., Ibrahim, A., \& Wang, X. (2015). Combination of Interventions Can Change Students' Epistemological Beliefs. Physical Review Special Topics - Physics Education Research, 11, $1-17$.

Kalman, J., \& Kalman, C .S. (1996). Writing to Learn. American Journal of Physics, 64, 954-956.

Karakostas, V., \& Hadzidaki, P. (2005). Realism vs. constructivism in contemporary physics: The impact of the debate on the understanding of Quantum Theory and its instructional process. Science \& Education, 14, 607-629. http://doi.org/10.1007/s11191-004-5156-1

Kuhn, D., \& Weinstock, M. (2002). What is epistemological thinking and why does it matter? In B. K. Hofer \& P. R. Pintrich (Eds.), Personal epistemology: The psychology of beliefs about knowledge and knowing (pp. 121-144). Mahwah, NJ: Erlbaum.

Kuhn, T. S. (1970). The structure of scientific revolutions (2nd ed.). Chicago, IL: The University of Chicago Press. (Originally published in 1962.)

Kuhn, T. S. (2000/1981). What are scientific revolutions? In J. Conant \& J. Haugeland (Eds.), The road since structure (pp. 13-32). Chicago, IL: The University of Chicago Press.

Lattery, M. J. (2016). Deep learning in introductory physics: Exploratory studies of modeling-based reasoning. Charlotte, NC: Information Age.

Leach, J. T., \& Scott, P. H. (2008). Teaching for conceptual understanding: An approach drawing on individual and sociocultural perspectives. In S. Vosniadou (Ed.), International handbook of research on conceptual change (pp. 647-675). New York, NY: Routledge.

Lee, G., Ha, S., \& Kalman, C. S. (2013). Workshop on Friction: Understanding and Addressing Students' Difficulties in Learning Science through a Hermeneutical perspective. Science \& Education, 22(6), 1405-1442.

Liu, P.-H. (2009). History as a platform for developing college students' epistemological beliefs of mathematics. International Journal of Science and Mathematics Education, 7, 473-499. http://doi.org/10.1007/s10763-008-9127-x.

Logger Pro. (2013). Plotting software. Retrieved from amdhttp://www.vernier.com/products/software/lp/]. Beaverton, OR: Vernier Software \& Technology. 
Madsen, A., McKagan, S. B., \& Sayre, E. C. (2015). How physics instruction impacts students' beliefs about learning physics: A meta-analysis of 24 studies. Physics Review Physics Education Research, 11. https://doi.org/10.1103/PhysRevSTPER.11.010115

Marra, R. (2005). Teacher beliefs: The impact of the design of constructivist learning environments on instructor epistemologies. Learning Environments Research, 8, 135-155.

Mason, L., \& Scrivani, L. (2004). Enhancing students' mathematical beliefs: An intervention study. Learning and Instruction, 14, 153-176. http://doi.org/10.1016/j.learninstruc.2004.01.002

Mazur, E. (1997a). Moving the mountain: Impediments to change. The Physics Teacher, 35(10), 1-4.

Mazur, E. (1997b). Understanding or memorization: Are we teaching the right thing? In J. Wilson (Ed.), Conference on the introductory physics course on the occasion of the retirement of Robert Resnick (pp. 113-124). New York, NY: Wiley.

Mazur, E. (2009). Farewell, lecture? Science, 323, 50-51.

Mazur, E. (2010). Confessions of a converted lecturer [Video talk]. Waterloo, Ontario: University of Waterloo, Perimeter Institute for Theoretical Physics.

McCaskey, T. L. (2009). Comparing and contrasting different methods for probing student epistemology and epistemological development in introductory physics. Unpublished doctoral dissertation. The University of Maryland, Department of Physics, College Park, MD. Retrieved from http://drum.lib.umd.edu/bitstream/handle/1903/9824/McCaskey_umd_0117E_10748.pdf?sequence=1\&isAllow ed $=\mathrm{y}$

McDonald, C. V. (2010). The influence of explicit nature of science and argumentation instruction on preservice primary teachers' views of nature of science. Journal of Research in Science Teaching, 47, 1137-1164. http://doi.org/10.1002/tea.20377

Muis, K. R. (2004). Personal epistemology and mathematics: A critical review and synthesis of research. Review of Educational Research, 74, 317-377.

Nelson, C. E. (1964). Critical thinking and collaborative learning. In K. Bosworth \& S. J. Hamilton (Eds.), Collaborative learning: Underlying processes and effective techniques (pp. 49-58). San Francisco, CA: Jossey-Bass.

Norris, S. P. (Ed.). (1992). The generalizability of critical thinking. New York, NY: Teachers College Press.

Ohlsson, S. (2011). Deep learning: How the mind overrides experience. New York, NY: Cambridge University Press.

Posner, G., Strike, K., Hewson, P., \& Gertzog, W. (1982). Accommodation of a scientific conception: Toward a theory of conceptual change. Science Education, 66, 211-227.

Radmacher, S. A., \& Latosi-Sawin, E. (1995). Summary writing: A tool to improve student comprehension and writing in psychology. Teaching of Psychology, 22, 113-115.

Sandoval, W. A. (2005). Understanding students' practical epistemologies and their influence on learning through inquiry. Science Education, 89, 634-656.

Schraw, G., \& Sinatra, G. M. (Eds.). (2004). Introduction [to special issue]: Epistemological development and its impact on cognition in academic domains. Contemporary Educational Psychology, 29, 95-102. http://doi.org/10.1016/j.cedpsych.2004.01.005

Slotta, J. D., \& Chi, M. T. H. (1999, April). Overcoming robust misconceptions through ontological training. Paper presented at the annual meeting of the American Educational Research Association, Montreal, Quebec.

Treagust, D., \& Duit, R. (2009). Multiple perspectives of conceptual change in science and the challenges ahead. Journal of Science and Mathematics Education in Southeast Asia, 32, 89-104.

Wandersee, J., Mintzes J., \& Novak J. (1994). Research on alternative student conceptions in science. In D. Gabel (Ed.), Handbook of research on science learning and learning (pp. 177-210). New York, NY: Macmillan.

Weinstein, M. (1993). Critical thinking: The great debate. Educational Theory, 43, 99-117.

Wilson, J. D., Buffa, A. J., \& Lou, B. (2007). College physics (7th ed.). Upper Saddle River, NJ: Pearson Prentice Hall. 
Windschitl, M. (2002). Framing constructivism in practice as negotiation of dilemmas: An analysis of the conceptual, pedagogical, cultural, and political challenges facing teachers. Review of Educational Research, 72, 131-175. http://doi.org/10.3102/00346543072002131

Windschitl, M. (2004). Folk theories of "inquiry": How preservice teachers reproduce the discourse and practices of an atheoretical scientific method. Journal of Research in Science Teaching, 41, 481-512. http://dx.doi.org/10.1002/tea.20010

Winter, D., Lemons, P., Bookman, J., \& Hoese, W. (2001). Novice instructors and student-centered instruction: Identifying and addressing obstacles to learning in the college science laboratory. Journal of Scholarship of Teaching and Learning, 2(1), 14-42.

Yacoubian, H. A., \& BouJaoude, S. (2010). The effect of reflective discussions following inquiry-based laboratory activities on students' views of nature of science. Journal of Research in Science Teaching, 47, 1229-1252. http://doi.org/10.1002/tea.20380. 